\title{
COAL MINING WASTE IS A VALUABLE SECONDARY RAW MATERIAL
}

\author{
U. Nazarbek, P.Abdurazova, S. Nazarbekova, M. Kambatyrov \\ and Y. Raiymbekov ${ }^{\bowtie}$ \\ M.Auezov South Kazakhstan University, 160000, Shymkent,Kazakhstan \\ ${ }^{\otimes}$ Corresponding Author: eplusr@bk.ru
}

\begin{abstract}
The article presents the results of complex studies of physical and chemical properties, such as sieve analysis, elemental and microstructural analysis, IR spectral analysis, and X-ray phase analysis. The results of the research allow concluding that coal mining waste is a valuable secondary raw material for the production of new multipurpose materials in the chemical and construction industries. Data obtained by scanning electron microscopy revealed the elemental composition of coal mining waste. As it turned out, the composition of the waste is dominated by carbon, silicon and iron. In addition, there are microelements in the form of magnesium, sulfur, and aluminum. All the data obtained will be used for the synthesis of humate-containing substances.

Keywords: Coal Mining Waste, Technogenic Waste, Humic Substances, Chemical Industry.
\end{abstract}

RASĀYANJ. Chem., Vol. 14, No.4, 2021

\section{INTRODUCTION}

The future of humanity largely depends on how environmental problems are solved today, the problems of harmonizing economic development with the preservation of the integrity of natural ecological systems and the entire diversity of life on Earth. It is obvious that at present, to solve environmental problems, problems of interaction between society and the environment, it is not enough to have only a system of authorized state bodies. We need a universal ecological culture so that all citizens of any country have an awareness of their responsibility to future generations.

The most important task of chemical technology is the rational use of natural resources using environmentally non-waste, resource-saving technologies. ${ }^{1}$

The main environmental problem in coal mining is the formation of a large amount of solid waste. During the construction of coal industry enterprises, especially open-pit mines and dumps, significant areas of the earth's surface are subject to changes. In particular, there is the removal of soil cover, the reduction of agricultural and forest land, the destruction of vegetation. To compensate for such damage, after the completion of mining operations, the disturbed land must be subjected to restoration work. ${ }^{2}$

In particular, waste rock dumps should be used, if possible, for laying the worked-out space. Technical and biological remediation should be carried out about the remaining dumps after laying. ${ }^{3}$

Kazakhstan's coal industry is one of the vital areas in the country's energy security. Kazakhstan is one of the ten countries with the largest coal deposits in the world. Kazakhstan's coal reserves are currently estimated at approximately 33 billion tons, which is about $4 \%$ of the world's reserves. At the same time, $62 \%$ of the deposits are brown coal, and $38 \%$ - stone coal. ${ }^{4}$

Coal mining in Kazakhstan begins in the middle of the XIX century during Tsarist Russia. It was then that the first deposits of brown coal were explored in the Southern region of Kazakhstan. From this time until the 60s of the last century, one of the largest deposits was Lenger. The reserve of the balance part of this field is more than 30 thousand tons. As a result of coal mining, more than 6 million tons of wastes were generated $^{5}$. A large amount of these types of waste is located on the territory of the city in the form of landfills (Fig.-1).

The main components of coal mining waste, according to the literature data ${ }^{6-8}$, are organic and inorganic substances. The composition contains compounds such as silicon, aluminum and calcium-containing substances. Functional groups in the composition of waste represent its organic part. 
In addition, there is a mixture of high-molecular and humic compounds consisting of aromatic and heterocyclic structures. Also, coal mining waste is a valuable secondary raw material for the production of humic substances ${ }^{9,10}$, a filler for concrete ${ }^{11}$, mineral fibers and pigments ${ }^{12}$, filtering granular materials. ${ }^{13}$

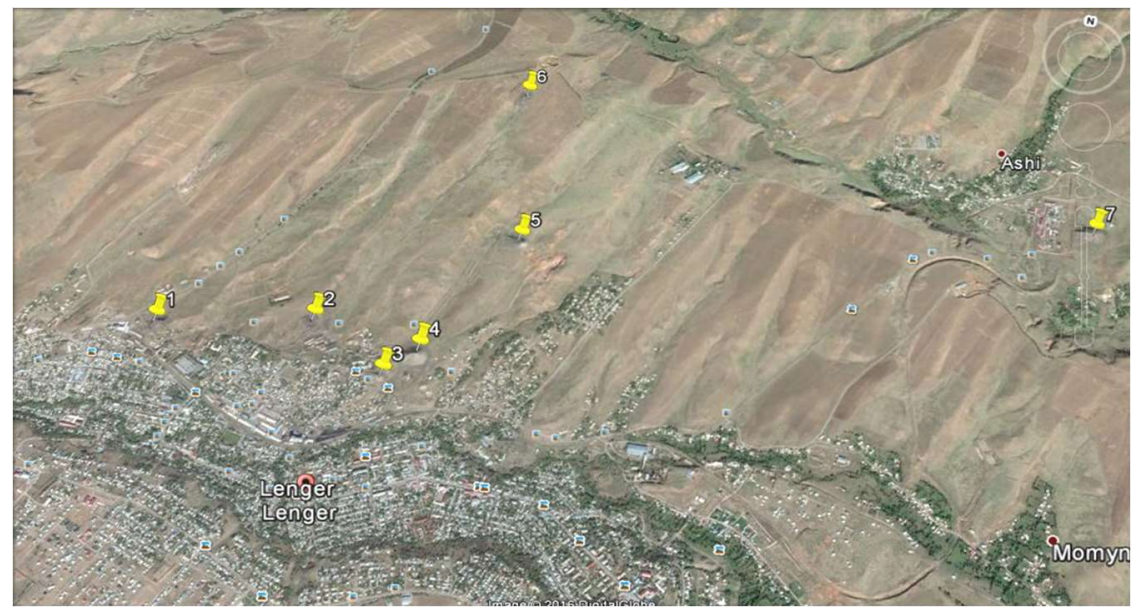

Fig.-1: Location of Coal Mining Waste Landfills on the Lenger Territory (Photo Obtained Using Google Map)

The coal mining waste from the Lenger field is multi-tonnage ballast formed during the extraction of local thermal coal during the five-year plans of the Soviet period of the country. To establish the possibility of their use as a rich raw material for the synthesis of humic substances, it is necessary to set up targeted studies to study its microstructure, physicochemical properties, elemental and organo-mineral composition.

\section{EXPERIMENTAL}

For a comprehensive study of the composition and physicochemical properties of coal mining waste, modern methods were used. The preparation of raw materials was carried out in two stages: grinding and sorting. The grinding of raw materials was carried out using a laboratory mill - a grinding complex. For the separation and sorting of raw materials by particle size, sieving was performed on a vibrating screen "Analizette 3". The dry sieving ranges are from 100 microns to $24 \mathrm{~mm}$.

Microstructural and element-weight studies were carried out using modern SEM equipment (JEOl scanning electron microscope, brand JSM6490 LV). ${ }^{14,15}$

IR-spectral analysis of coal mining waste was carried out on the device Shimadzu IR Prestige-21 FourierIR spectrometer with the prefix of the disturbed total internal reflection (NPV) Miracle of PikeTechnologies. ${ }^{16,17}$

X-ray phase analysis was performed on the DRON-3 device, and the radiographs were decoded using the ASTM card file and the Mikheev X-ray detector. ${ }^{18,19}$

\section{RESULTS AND DISCUSSION}

Figure-2 shows the sieve analysis results of coal mining waste from the Lenger field.From the data in Fig.-2, it follows that about $1 / 3$ of the coal mining waste is accounted for by the average fraction with particle sizes of $3.50-0.71 \mathrm{~mm}$. In the total mass of the waste, about $14 \%$ are large fractions with dimensions of more than 7.10-3.50 mm. Small particles account for about $47 \%$. The bulk of the coal mining waste is made up of fractions with dimensions: $2.00-1.40 \mathrm{~mm} ; 1.40-1.00 \mathrm{~mm} ; 1.00-0.71 \mathrm{~mm}$.

The elemental composition and microstructure of coal mining waste from the Lenger deposit were studied using a scanning electron microscope. The surfaces of the studied samples were studied in different spectra at 40x magnification. Table-1 and Fig.-3 show the elemental composition of coal mining waste from the Lenger deposit with a micrograph of the surface and diffraction peaks of the elements.

As follows from the data in Table-1 and Fig.-3, the elemental composition of the mineral part of the coal mining waste of the Lenger deposit is characterized by significant inclusions of silicon, aluminum, and to a lesser extent iron, sulfur, and calcium. 
RASĀYAN J. Chem.

Vol. 14 | No. 3 |2171-2176| October - December | 2021

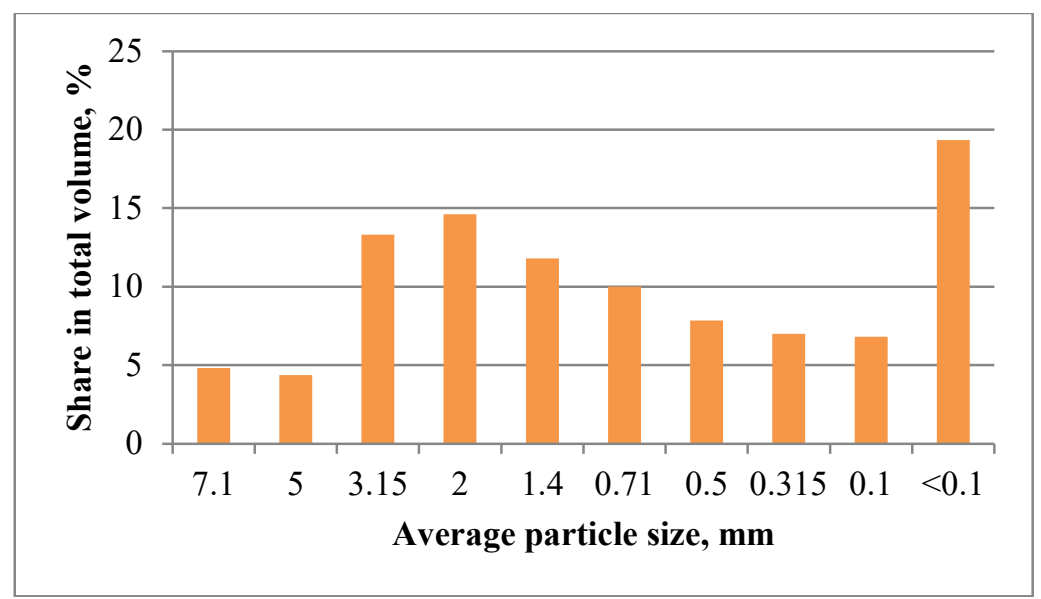

Fig.-2: Results of the Sieve Analysis of Coal Mining Waste

In the microstructure of the sample, these minerals are represented by indistinct irregular clusters of crystals. Irregular hexagonal single minerals indicate the presence of calcium aluminates. Dark clusters around fine-crystalline aluminate minerals are characteristic of calcium and silicon ferrite compounds. In the general structure of the studied spectrum, the presence of quartz minerals is confirmed by small chain clusters. Here, carbon compounds are represented by intermediate dark clusters. ${ }^{14,15}$
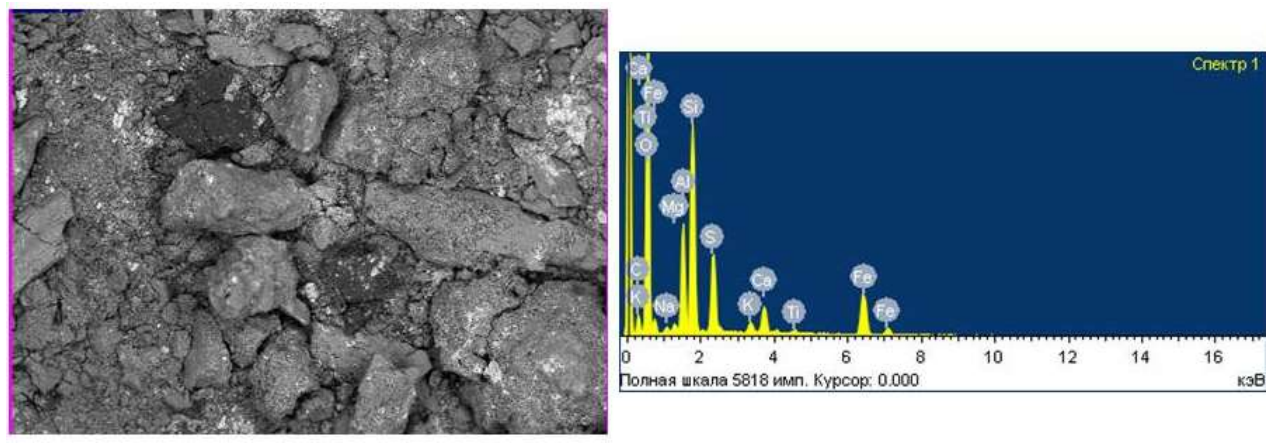

Fig.-3: Microstructure of Coal Mining Waste

Table-1: Elemental Composition of Coal Mining Waste

\begin{tabular}{c|c|c|c}
\hline Element & Weight Composition, $\%$ & Oxides & In Terms of Oxides, $\%$ \\
\hline $\mathrm{O}$ & 39.24 & - & - \\
\hline $\mathrm{C}$ & 39.34 & - & - \\
\hline $\mathrm{Na}$ & 0.15 & $\mathrm{Na}_{2} \mathrm{O}$ & 0.20 \\
\hline $\mathrm{Mg}$ & 0.46 & $\mathrm{MgO}$ & 0.76 \\
\hline $\mathrm{Al}$ & 4.52 & $\mathrm{Al}_{2} \mathrm{O}_{3}$ & 8.54 \\
\hline $\mathrm{Si}$ & 8.48 & $\mathrm{SiO}_{2}$ & 18.14 \\
\hline $\mathrm{S}$ & 2.09 & $\mathrm{SO}_{3}$ & 5.2 \\
\hline $\mathrm{K}$ & 0.70 & $\mathrm{~K} O$ & 0.84 \\
\hline $\mathrm{Ca}$ & 1.29 & $\mathrm{CaO}$ & 1.80 \\
\hline $\mathrm{Ti}$ & 0.35 & $\mathrm{TiO}_{2}$ & 0.58 \\
\hline $\mathrm{Fe}$ & 3.37 & $\mathrm{Fe}_{2} \mathrm{O}_{3}$ & 4.81 \\
\hline
\end{tabular}

IR-spectral analysis of coal mining waste from the Lenger field was performed using the ShimadzuIRPrestige-21 instrument. The results of the studies are shown in Fig.-4.

The IR spectra of the studied sample of coal mining waste from the Lenger field are characterized by intense peaks of a wide absorption band with satellites in the areas of 500-900 cm-1 and 2600-3700 $\mathrm{cm}^{-1}$. It should be noted that the wavelengths in the absorption region of $550-700 \mathrm{~cm}^{-1}$ are typical for alkanes 
RASĀYAN J. Chem.

Vol. 14 | No. 3 |2171-2176| October - December | 2021

and alenes with the $\mathrm{RC} \equiv \mathrm{CH}$ bond types, and $850-900 \mathrm{~cm}^{-1}$ for compounds of the alkane and alene series with the $\mathrm{RC}=\mathrm{C}=\mathrm{CR}$ bond types. Intense absorption peaks in the region of $2600-3700 \mathrm{~cm}^{-1}$ characterize the carbonyl groups of the aromatic series of the types $\mathrm{RCH}_{2}-\mathrm{COOH}, \mathrm{RC}=\mathrm{C}-\mathrm{COOH}$. The valence vibrations of the $-\mathrm{OH}$ group observed in the absorption region of $3080-3700 \mathrm{~cm}^{-1}$ are also noticeable. Diffraction waves in the region of $1080-1090 \mathrm{~cm}^{-1}$ are characteristic of organosilicon compounds of the Si-O-C, SiO-Si type. ${ }^{16}$

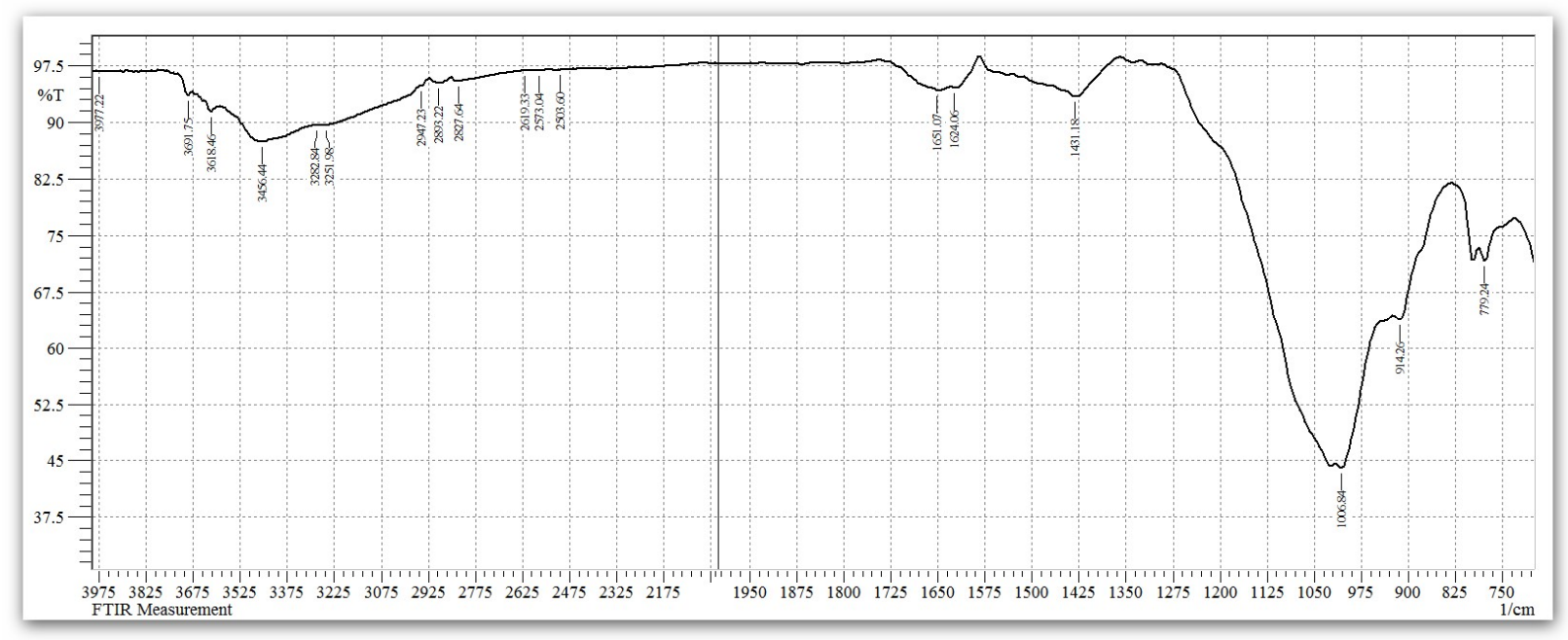

Fig.-4: IR Spectra of Coal Mining Waste

Table-2: The Peaks of the IR Spectra

\begin{tabular}{c|c|c|c|c|c|c|c}
\hline No. & Peak & Intensity & Corr. Intensity & Base $(\mathrm{H})$ & Base $(\mathrm{L})$ & Area & Corr. Area \\
\hline 1 & 779.24 & 71.631 & 2.329 & 786.96 & 732.95 & 6.705 & 0.147 \\
\hline 2 & 914.26 & 63.733 & 2.140 & 921.97 & 833.25 & 11.793 & 0.225 \\
\hline 3 & 1006.84 & 44.054 & 2.226 & 1014.56 & 925.83 & 22.817 & 0.400 \\
\hline 4 & 1431.18 & 93.391 & 2.734 & 1465.90 & 1361.74 & 2.084 & 0.622 \\
\hline 5 & 1624.06 & 94.538 & 0.507 & 1627.92 & 1585.49 & 0.723 & 0.136 \\
\hline 6 & 1651.07 & 94.248 & 1.135 & 1724.36 & 1631.78 & 1.845 & 0.308 \\
\hline 7 & 2503.60 & 96.939 & 0.018 & 2507.46 & 2495.89 & 0.155 & 0.000 \\
\hline 8 & 2573.04 & 96.919 & 0.012 & 2576.90 & 2549.89 & 0.365 & 0.001 \\
\hline 9 & 2619.33 & 96.821 & 0.021 & 2627.05 & 2576.90 & 0.693 & 0.003 \\
\hline 10 & 2827.64 & 95.464 & 0.593 & 2850.79 & 2630.91 & 3.774 & 0.275 \\
\hline 11 & 2893.22 & 95.238 & 0.650 & 2920.23 & 2854.65 & 1.320 & 0.130 \\
\hline 12 & 2947.23 & 94.819 & 0.148 & 2951.09 & 2924.09 & 0.560 & 0.011 \\
\hline 13 & 3251.98 & 89.630 & 0.153 & 3259.70 & 2954.95 & 11.403 & 0.696 \\
\hline 14 & 3282.84 & 89.572 & 0.040 & 3290.56 & 3263.56 & 1.287 & 0.003 \\
\hline 15 & 3456.44 & 87.392 & 3.571 & 3591.46 & 3294.42 & 14.995 & 2.579 \\
\hline 16 & 3618.46 & 91.382 & 1.030 & 3637.75 & 3603.03 & 1.274 & 0.084 \\
\hline 17 & 3691.75 & 93.610 & 1.087 & 3726.47 & 3680.18 & 1.074 & 0.092 \\
\hline 18 & 3977.22 & 96.748 & 0.051 & 3981.08 & 3691.79 & 0.274 & 0.002 \\
\hline
\end{tabular}

X-ray phase analysis of coal mining waste was carried out on the DRON-3 device, and the radiographs were decoded using the ASTM card file and the Mikheev X-ray detector (Fig.-5).

Analysis of the X-ray image shows that the structure of the test sample is amorphous. Diffraction maxima with values of interplanar distances $\mathrm{d} / \mathrm{n}=4.24-3.34-2.45-2.28-1.81-1.53 \hat{\mathrm{A}}$. They indicate the presence in the crystal structure of the sample of quartzite- $\mathrm{SiO}_{2}$, which is the main component. The composition of the test sample contains in significant quantities: iron oxide- $\mathrm{Fe}_{2} \mathrm{O}_{3}$, with diffraction maxima $\mathrm{d} / \mathrm{n}=2.69$ 2.51-2.43-2.20-1.84-1.69 $\hat{\mathrm{A}}$ and gypsum- $\mathrm{CaSO}_{4} \cdot 2 \mathrm{H}_{2} \mathrm{O}$, which is characterized by diffraction maxima $\mathrm{d} / \mathrm{n}=7.7-3.81-3.06-2.68-2.07-1.66 \hat{\mathrm{A}}$. The presence of coal impurities is indicated by diffraction maxima with low-intensity $\mathrm{d} / \mathrm{n}=3.35-2.02-1.68-1.54 .{ }^{19}$ 
RASĀYAN J. Chem.

Vol. 14 | No. 3 |2171-2176| October - December | 2021

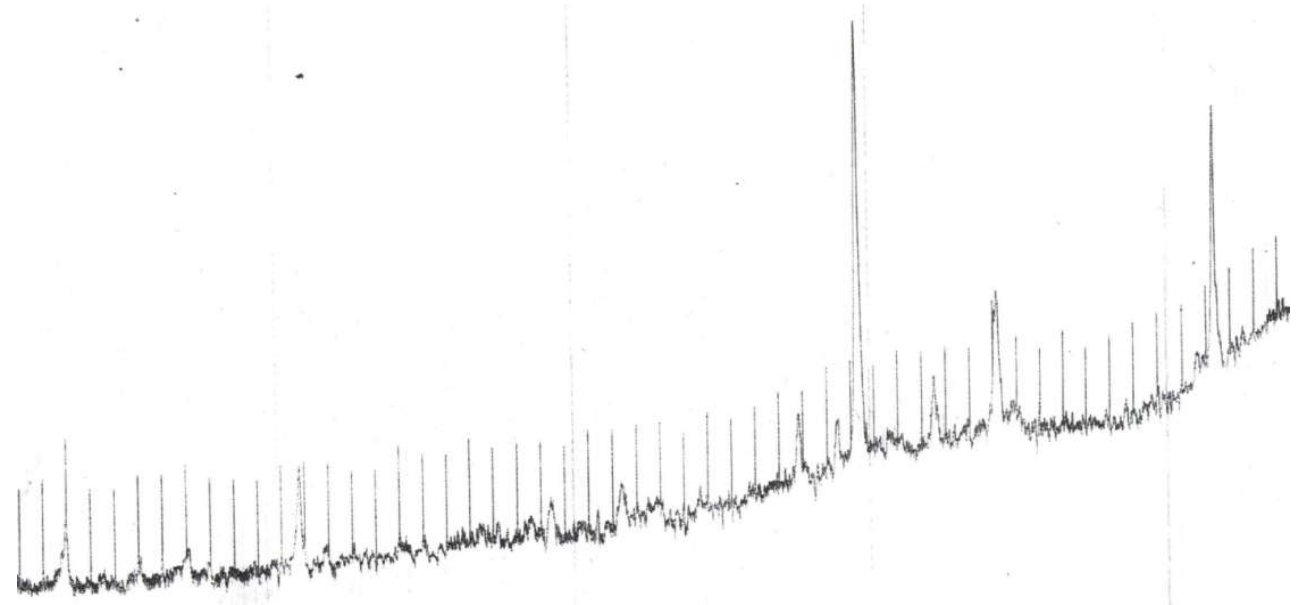

Fig.-5: X-ray Image of Coal Mining Waste

Coal mining waste has also been the subject of research in other scientific manuscripts. The results of the thermal analysis revealed the content of the main compounds: aluminate, silicon - and sulfur-containing in the composition of coal mining waste. ${ }^{20}$ The studied mineralogical structure indicates the presence of various minerals, such as pyrite, calcite, and aluminate in the composition of coal mining waste ${ }^{7}$. These data supplement the results of our research, and also substantiate the applicability of these types of waste for the production of multi-purpose products.

\section{CONCLUSION}

Using modern technical means and methods of physical and chemical analysis, the composition and structure of coal mining waste from the Lenger field were studied. It is established that coal mining waste is a valuable secondary raw material suitable for processing them into humate containing complex organomineral fertilizers and feed additives. It is also shown that the waste of coal mining Lenger deposits has amorphous structure.

\section{ACKNOWLEDGEMENT}

This research is funded by the Science Committee of the Ministry of Education and Science of the Republic of Kazakhstan (Grant No. AP09057884).

\section{REFERENCES}

1. M.Peter, Journal of Hazardous Materials, 37(1), 1 (1994), https://doi.org/10.1016/03043894(94)85028-3

2. Y. Taha, M. Benzaazoua, R. Hakkou and M. Mansori, Minerals Engineering, 107, 123 (2017), https://doi.org/10.1016/j.mineng.2016.09.001

3. L. Haibin and L. Zhenling, Resources, Conversation and Recycling, 54(12), 1331 (2010), https://doi.org/10.1016/j.resconrec.2010.05.005

4. Kh. Myrzabaeva and I. Sataev, Nauka I ObrazovanieYuzhnogoKazahstana, 3, 96 (1996).

5. B. Myrzakhmetova and U.Besterekov, In Proceedings of International Scientific-practical Conference "Auezov Readings-8", Shymkent, Kazakhstan, pp. 135 (2009).

6. Z.Bian, J. Dong, S. Lei, H. Leng, S. Mu and H.Wang, Environmental Geology, 58, 625 (2009), https://doi.org/10.1007/s00254-008-1537-0

7. M.Amrani, Y.Taha, Y. El Haloui, M.Benzaazoua and R.Hakkou, Minerals, 10(10), 851 (2020), https://doi.org/10.3390/min10100851

8. A.Modarres and M. Rahmanzadeh, Construction and Building Materials, 66, 476 (2014), https://doi.org/10.1016/j.conbuildmat.2014.06.002

9. M. Kambatyrov, U. Nazarbek, P. Abdurazova, S. Nazarbekova and Y. Raiymbekov, Rasayan Journal of Chemistry, 13(3), 1308 (2020), https://doi.org/10.31788/RJC.2020.1335729

10. Y. Raiymbekov, U. Besterekov, U. Nazarbek and P. Abdurazova, Rasayan Journal of Chemistry, 14(1), 46 (2021), https://doi.org/10.31788/RJC.2021.1416080 
RASĀYAN J. Chem.

Vol. 14 | No. 3 |2171-2176| October - December | 2021

11. N. Zhanikulov, T. Khudyakova, B. Taimassov, A. Kolesnikov and R. Karshygayev, Eurasian Chemico-Technological Journal, 21(4), 333 (2019), https://doi.org/10.18321/ectj890

12. H. Anawar, V. Strezov and T. Adyel, Sustainable and Economic Waste Management, CRC Press, Florida, p.16(2019), https://doi.org/10.1201/9780429279072

13. R. Geremias, R. Laus, J. M. Macan, R. C. Pedrosa, C. M. Laranjeira, J. Silvano and F. V. Favere, Environmental Technology, 29(8), 863 (2008), https://doi.org/10.1080/09593330802015409

14. S.J.B.Reed, Electron Microprobe Analysis and Scanning Electron Microscopy in Geology, Cambridge University Press, Cambridge, Great Britain, p.240 (1996).

15. A. Ul-Hamid, A Beginners' Guide to Scanning Electron Microscope, Springer, Switzerland, p. 402 (2018).

16. Shimadzu Data Processing Reference Manual, Shimadzu Corporation, Tokyo, Japan, p.188 (2020).

17. B.N. Tarasevich, Osnovy IK spektroskopii s preobrazovaniemFur'e. Podgotovka prob v IK spektroskopii [in Russian: Fundamentals of Fourier transform IR spectroscopy. Sample preparation in IR spectroscopy], Lomonosov Moscow State University, Moscow, p.22 (2012).

18. V.I. Mikheyev, Rentgenometricheskijopredelitel' mineralov [in Russian: Radiometric mineral detector], State Scientific and Technical Publishing House of Literature on Geology and Subsurface Protection, Moscow, p.862 (1957).

19. T.Khabas and T.Vakalova, X-Ray Phase Analysis. Methodological Guidelines. Tomsk Polytechnical University, Tomsk, Russian Federation, p.40 (2017).

20. B.M. Smailov, O.K.Beisenbayev, A.S.Tleuov, A.A.Kadirbaeva, B.S. Zakirov and B.Mirzoyev, Rasayan Journal of Chemistry, 13(3), 1372 (2020), https://doi.org/10.31788/RJC.2020.1335726

[RJC-6416/2021] 